Jahangir, his successor, was born of a Rajput princess. It is worth remembering that his reign coincides almost exactly with that of Elizabeth of England. At a time when Europe still found the methods of the rack and stake acceptable, he instituted and enforced religious toleration. He grappled with the horrors of suttee two hundred years before Bentinck abolished it. He was the patron of learning and the arts. His justice knew no distinction of caste or creed or colour. Such was the man, who, while he lived, united India in mutual service. The fourth centenary of Akbar's birth will be celebrated by a meeting arranged by the British Council, the Royal Asiatic Society, the East India Association and the India Society to be held in the rooms of the Royal Society on November 23.

\section{Discovery of a Nova}

A TELEGRAM from Lund announces the discovery of a nova, magnitude 2, by Finsler and Nakahara. It is about $5^{\circ}$ north of Puppis. The telegram is dated November 13, but the time of discovery is not stated. Before receiving the telegram a telephone message which was sent by Mr. G. Ellis, Llandudno Junction, was received at the Royal Observatory, Greenwich, and this announced that Mr. Ellis, observing from a height of $400 \mathrm{ft}$. above sea-level, had discovered the nova on Nov. 13d. 4 h. 25m. U.T., its approximate position being, R.A., $8 \mathrm{~h}$. $10 \mathrm{~m}$., Dec. $-34^{\circ}$. Owing to its high southern declination it will not be an easy object to see in Great Britain. It crosses the meridian about $4 \mathrm{~h}$. $15 \mathrm{~m}$. U.T. on November 21, and in the latitude of Greenwich its greatest altitude does not exceed $4 \cdot 5^{\circ}$. Mr. Will Hay has reported that he has observed the nova with the naked eye.

\section{Documentation and Microfilm}

THE Proceedings of the British Society for International Bibliography, Parts 1 and 2, contain the papers and discussions at the twenty-second and twenty-third ordinary meetings on March 5 and April 23 last, respectively. In Part 1, Miss M. Shaw's paper "Documentation in an Industrial Laboratory" describes the library and information service in the laboratories of Messrs. J. Lyons and Co., Ltd. The function of this library is to keep the chemical staff supplied with the most recent scientific and technical literature, to see that this is adequately catalogued and indexed, and to supply information, as well as prepare bibliographies and translations. Any books borrowed must be in the laboratories during the day so that they are available for reference if required. With regard to abstracting, the actual reading of the periodicals and selection of matter to be indexed is carried out by the chemists themselves, the periodicals concerned being issued to the sections of the laboratory in turn, for periods of 2-3 days, and 7 days for the final section, which is responsible for noting anything missed by other sections. Indexing is carried out daily in the library before re-issuing a periodical. For copying scientific papers, the LumiereVan der Grinten diazo process is used and has given very satisfactory results since July 1938.

Part 2 of the Proceedings contains a paper by B. K. Johnson describing four pieces of apparatus for use with microfilming processes. These consist of a hand viewer for the recognition of titles and general identification of the film, a viewer for table use, a microfilm projector for use by the typist when typewritten copies of a document recorded on microfilm are required, and a camera for the photography of documents, etc. In a written communication in the discussion, Mr. E. H. Lindgren stressed the importance of proper safeguards in the storage of the film and referred to an intensive technical examination of the films in his possession which is being carried out with the view of obtaining fuller information on the storage question. Mr. K. S. Smith's paper in the same part describes the airgraph service, Mr. H. J. Dowden the Gesteprint process for duplicating foreign periodicals, etc., in which the stencils are prepared by a photographic process, and a paper by $\mathrm{H}$. Rottenburg on "The Typewriter as the Foundation of the Printed Book" outlines the possibilities of replacing printer's type by a typewriter and discusses the advantages.

\section{Polarography}

Polarographic methods continue to attract attention in Great Britain. Much knowledge has already been obtained and a concise summary of this, written in a simple objective manner, is to be found in a pamphlet, "Cambridge Polarograph", recently published by the Cambridge Instrument Company. For its size this pamphlet covers a great deal of ground and, if the theoretical background of polarography is largely omitted, this is compensated for by the presence of a considerable bibliography which contains references to most of the important papers on the subject. The difficulties of the polarographic method are not unduly emphasized ; nevertheless, most of the major pitfalls are mentioned and it is frequently made clear that modifications of technique must be very critically tested. Use of the polarograph for the performance of amperometric titrations has not been overlooked.

A relatively small part of the pamphlet is devoted to a description of the Cambridge polarograph, and it is a pity that a wiring diagram of the instrument is omitted. Clearly, however, satisfactory electrical equipment is provided in a compact form to meet the needs of a present-day user of the polarograph. The text of the pamphlet is well illustrated with reproductions of actual polarograms, which give a very fair idea of the possibilities of the instrument and will no doubt stimulate the efforts of new users of the Cambridge polarograph. A table and chart of the half-wave potentials of inorganic substances, and the bibliography already mentioned, add to the value of the publication.

\section{Spectroscopy in Astrophysics}

DURING a conference on spectroscopy arranged by the University of Chicago on June 22-25, several papers described results of recent research with the aid of the spectroscope. A short account of these papers is given in Sky and Telescope, September, by Dorrit Hoffleit. Dr. Andrew McKellar, of the Dominion Astrophysical Observatory, has made a critical study of the intensities of bands in the spectra of Comet Hassel (1939d) and Comet Cunningham (194cc). These bands correspond to temperatures ranging roughly from $200^{\circ}$ to $2,000^{\circ} \mathrm{K}$., and further research is desirable to explain this anomaly. The use of the spectroscope in settling the composition of planetary atmospheres has been followed by numerous theories to account for the diversity in the atmospheres of the planets, assuming that they all 
started their evolutionary course as homogeneous fluid masses with temperatures of several thousand degrees. Dr. Rupert Wildt discusses this problem in an interesting paper, but, as might be expected with a subject of such complexity, there is a large amount of speculation in his theories. Dr. C. T. Elvey reports on spectrophotometric and photo-electric studies of the night sky, and discusses the permanent or 'nonpolar' aurora, which is much less spectacular than the better known northern or southern lights. The spectra indicate that atoms or molecules of oxygen, sodium, nitrogen, nitric oxide, water, and sometimes ionized nitrogen are involved. Spectrophotometric studies, in which Dr. Alice Farnsworth collaborated, refer to radiations originating about 800 miles above the earth's surface. Photo-electric observations concern radiations from altitudes of about 200 miles. Infra-red observations of the intensity of the light of the night sky show that there is sometimes a steady decrease throughout the night, and also that such observations are associated with times when terrestrial magnetic activity is low. It is suggested that this regular variation may be explained on the theory that the radiation is caused by the release of energy when oxygen atoms combine to form oxygen molecules.

\section{Recent Earthquakes}

AN earthquake with epicentre in the Songea District (Livingstone Mountains) near Lake Nyasa, Tanganyika, was reported from Dar es Salaam on November 8 . It is said to have been the most serious for many years and wrecked many buildings and a Roman Catholic mission. Damage is estimated to have been near $£ 3,000$. No casualties have been reported.

Dr. Perry Byerly of the University of California reported the registration of a very large earthquake by the seismographs at Berkeley at 8.2 a.m. Eastern War Time on November 10. The epicentre was estimated to have been 9,500 miles from Berkeley.

During October 1942 only two important earthquakes have been registered by the seismographs at Kew Observatory. These were on October 20 and 26, respectively. The former began recording at 23h. $35 \mathrm{~m}$. 55s. U.T. and attained a ground amplitude of $195 \mu$ at $00 \mathrm{~h} .27 \mathrm{~m}$. 06s. on October 21 . The epicentral distance from Kew may have been 11,200 $\mathrm{km}$., but the analysis is tentative since the record was interrupted by large microseisms. The latter began recording with compressional iP on all three components at $21 \mathrm{~h} .21 \mathrm{~m}$. $19 \mathrm{~s}$. U.T. and attained a maximum ground amplitude at Kew of $89 \mu$ at $2 \mathrm{lh}$. $56 \mathrm{~m}$. 57s. U.T., the recording being complete at 23h. 55m. U.T. The epicentre may have been 8,700 $\mathrm{km}$. from Kew, almost in a south-westerly direction. On October 30 an earthquake shock of considerable strength was reported from Switzerland. No further details are so far available.

\section{Reginald Farrer (1880-1920).}

THE pre-war vogue of rock gardens owes much to the enthusiasm of Reginald Farrer (1880-1920). His home was in Ingleton, Yorkshire, where the natural scenery is itself a rock garden, and Farrer began to combine this beauty with horticultural concentration of colour at the early age of fourteen. Two short papers by E. H. M. Cox, one of Farrer's collaborators, and Humphrey Denham (J. Roy. Hort. Soc., 67, Pt. $9 ; 1942$ ) portray Farrer's life and his contributions to gardening. Having exhausted the possibilities of the
European Alps, he made two expeditions to China; from that country he introduced the beautiful threepenny-bit rose (R. F'arreri), Buddleia alternifolia, several species of Rhododendron, Aster Farreri, Viburnum fragrans, and many others. Aside from his botanical contributions, Farrer's life is an outstanding study in determination; he had very poor physique and was "a Yorkshireman with an inferiority complex", yet his contributions to horticulture rank among the greatest.

\section{John Amos Comenius}

ON October 24, 1941, the tercentary of the visit of John Amos Comenius to England was commemorated at Cambridge, and in NATure of November 22 there appeared an account of Comenius, his life and work, by Dr. Gerald Druce. It was then intended that the papers read at the commemoration would be published in permanent form. This inten. tion has been carried out by the appearance of a volume entitled "The Teacher of Nations", containing all the papers read, whether short or long (Cambridge University Press, 5s, net). The volume, which is edited by Dr. Joseph Needham, contains also a chronological table showing the events in the life of Comenius, by Dr. R. F. Young, and a select bibliography of the works of Comenius by Anne Heyberger.

\section{British Rheologists' Club}

AT the annual general meeting of the British Rheologists' Club, held on November 6, the following officers were elected : President, Dr. C. F. Goodeve; Honorary Secretary, Dr. G. W. Scott Blair ; Honorary Treasurer, Dr. V. G. W. Harrison. After the formal business, Prof. E. H. Rideal gave an informal address on "Solutions of Macro-molecules". Later, simple demonstrations were given by some members of the Committee to illustrate the Club's "Table of Deformations" (NATURE, 149, 702; June 20, 1942).

\section{Colonial Service Appointments}

THE following appointments and promotions in the Colonial Service have recently been made: E. G. Cripps, agricultural officer, Nyasaland; G. R. Fenton, assistant conservator of forests, Sierra Leone; J. F. Hughes, assistant conservator of forests, Tanganyika Territory; C. C. B. Brown, veterinary officer, Tanganyika Territory; L. C. Stones, veterinary officer, Gold Coast; J. N. R. Brown (agricultural officer), senior agricultural officer, Tanganyika Territory.

\section{Work of Scientific Men of the United Nations}

THE Association of Scientific Workers is holding a conference on "Scientists of the United Nations and the War Effort" at Gas Industry House, I Grosvenor Place, S.W.1, on December 5 (2.30 p.m.) and 6 (11 a.m.), under the chairmanship of Sir Richard Gregory, president of the British Association. Prominent scientific workers from more than fifteen countries will give addresses on the destruction and distortion of science in the oppressed countries and will show by contrast the contribution of scientific men of the United Nations who are in Great Britain to the war effort. Applications for invitations should be sent to the secretary, Foreign Scientists Committee, Association of Scientific Workers, Hanover House, 73 High Holborn, W.C.1. 